Short communication

\title{
Genetics of milk fatty acid groups predicted during routine data recording in Holstein dairy cattle
}

\author{
Mauro Penasa ${ }^{\text {a,* }}$, Francesco Tiezzi $^{\mathrm{b}}$, Paolo Gottardo ${ }^{a}$, Martino Cassandro ${ }^{\text {, }}$ \\ Massimo De Marchi ${ }^{a}$ \\ a Department of Agronomy, Food, Natural resources, Animals and Environment, University of Padova, Viale dell'Università 16, 35020 \\ Legnaro, $P D$, Italy \\ bepartment of Animal Science, North Carolina State University, Raleigh 27695, USA
}

\section{A R T I C L E I N F O}

\section{Article history:}

Received 30 July 2014

Received in revised form

12 December 2014

Accepted 16 December 2014

Keywords:

Milk fatty acid

Holstein

Heritability

Genetic correlation

\begin{abstract}
A B S T R A C T
The aim of this paper was to estimate genetic parameters for groups of milk fatty acids (FA), namely saturated (SFA), unsaturated (UFA), monounsaturated (MUFA) and polyunsaturated (PUFA), in Holstein cows. Mid-infrared spectroscopy (MIRS) was used to predict FA groups ( $\mathrm{g} / 100 \mathrm{~g}$ of milk) of 72,848 samples recorded on 17,873 cows between September 2011 and November 2012. Univariate and multivariate models were implemented in a Bayesian framework to estimate (co)variance components for SFA, UFA, MUFA, PUFA, daily milk yield, milk fat and milk protein. Statistical models included fixed effect of parity by stage of lactation, and random effects of herd-test-date, cow permanent environmental, animal additive genetic and residual. Posterior means of heritability estimates for SFA, UFA, MUFA and PUFA were 0.246, 0.069, 0.082 and 0.078, respectively. Estimates of genetic correlations between FA groups ranged from 0.405 (SFA and PUFA) to 0.952 (MUFA and UFA). The increase of fat content led to an increase of all groups of FA, in particular SFA, with undesirable effects on the healthy quality of the product. The study highlighted the existence of exploitable additive genetic variation for groups of FA routinely predicted by MIRS and thus there is potential to address the selection to healthy milk FA composition.
\end{abstract}

(c) 2014 Elsevier B.V. All rights reserved.

\section{Introduction}

The saturated fatty acids (SFA) increase blood cholesterol, which in turn is associated with increased blood pressure, risk of cardiovascular diseases, obesity, and insulin resistance (Mensink et al., 2003; Rasmussen et al., 2006; Sacks and Katan, 2002; Vessby et al., 2001). This has often led to the

\footnotetext{
* Corresponding author. Tel.: +39049827 2629;

fax: + 390498272633

E-mail addresses: mauro.penasa@unipd.it (M. Penasa), fra.tiezzi@gmail.com (F. Tiezzi),

paolo.gottardo86@gmail.com (P. Gottardo),

martino.cassandro@unipd.it (M. Cassandro),

massimo.demarchi@unipd.it (M. De Marchi).

http://dx.doi.org/10.1016/j.livsci.2014.12.014

1871-1413/৫ 2014 Elsevier B.V. All rights reserved.
}

"demonization" of bovine milk fat (MF), as it typically contains 70\% SFA, 25\% monounsaturated FA (MUFA), and $5 \%$ polyunsaturated FA (PUFA).

Fat composition of cow milk is influenced by metabolic status and stage of lactation of the animal, as negative energy balance directly impacts the presence of unsaturated FA (UFA). The mobilization of fat reserves has been found to increase the content of UFA in milk (Gross et al., 2011; Samková et al., 2012), whereas contents of SFA decrease rapidly till the peak of lactation and then increase weakly (Soyeurt et al., 2008). Stoop et al. (2009) found similar results, showing that proportions of SFA, in particular C6:0-C14:0, peaked around the third month of lactation. Seasonality is another factor which determines milk FA composition, with a decrease of SFA content and 